\title{
Educação infantil dialógica e não-violenta
}

\author{
Dialogic and nonviolent children's education
}

Prof. Dra. Alessandra Maria Martins Gaidargi

Pós-doutoranda em educação - PPGE

Universidade Nove de Julho - São Paulo/SP

alessandra.gaidargi@gmail.com

Resumo: Este artigo tem como objetivo provocar a reflexão sobre as violências que acontecem no âmbito escolar, especialmente na Educação Infantil, e seus possíveis desdobramentos. A violência escolar é objeto de estudo de teorias revisitadas neste trabalho, e ainda que não se possa desvincular a violência escolar daquelas que cercam a criança, como a social e a familiar, é importante propor caminhos diferentes para as relações dentro da escola. Apontamos, neste estudo, a possibilidade do trabalho com a teoria da comunicação não-violenta nas escolas enquanto facilitadora das relações democráticas, e apresentamos algumas aproximações desta com a teoria freiriana, na proposição de uma educação dialógica. A proposta para uma educação dialógica e não-violenta surge para apresentar um caminho para diminuição da violência partindo de dentro para fora dos muros escolares, num novo olhar sobre as relações nas escolas.

Palavras-chave: Educação infantil. Escola. Não-violência.

Abstract: This article aims to provide a reflection about the violence that happens in schools, especially in early childhood education, and its possible consequences. School violence is the object of study of theories revisited in this work, and although it is not possible to detach school violence from other violences around the child, such as social and family ones, it is important to propose different paths for relationships within the school. In this study, we point out the possibility of working with the theory of nonviolent communication in schools as a facilitator of democratic relations, and present some linearities of this with Freire's theory, in the proposition of a dialogic education. The proposal for a nonviolent education is to present a way to reduce violence from the inside out of school walls, in a new conception about school relations.

Keywords: Child education. School. Nonviolence. 


\section{Introdução}

A educação enfrenta, atualmente, um dos grandes desafios da modernidade: a violência. Evidentemente a violência nas diversas relações humanas não é uma questão exclusiva da modernidade, mas a forma que se expandiu nos últimos tempos é preocupante, e nos leva à reflexão sobre a coparticipação de todos os integrantes de uma sociedade nos atos de violência que nela acontecem, ainda que não sejam os praticantes específicos de cada um deles.

A violência dentro da escola reflete a violência que atinge a comunidade escolar, nas famílias e entre os grupos sociais. Charlot (2002) afirma que a questão da violência na escola é histórica, porém, atualmente, o movimento antigo assume novas formas, e que "a escola não se apresenta mais como um lugar protegido, até mesmo sagrado, mas como um espaço aberto às agressões vindas de fora" (id. ib., p.433). A perda da legitimidade da escola como detentora de conhecimento na atualidade também colabora para este cenário.

No Brasil atualmente vivenciamos o aumento da violência social, que repercute nas salas de aula. Dados apresentados por Sposito (2001) mostram que a violência escolar no Brasil é uma realidade estudada desde a década de 1980, e que tem se modificado. Outros estudos apontados por Nesello at all (2014) retratam a prevalência e a frequência elevada do fenômeno da violência escolar no Brasil, inclusive com implicações a integridade física e psíquica de alunos e professores. Em parte, a documentação deste aumento demonstra nossa capacidade crescente em reconhecer a violência que ocorre na escola em suas variações, mas também é um indicativo factual de que os envolvidos nos processos educativos têm se tornado cada vez mais violentos.

Ao abordarmos a violência na educação e na escola temos de nos atentar a todas as suas formas. Desde as violências diretas, caracterizadas pelas agressões físicas e verbais, às formas veladas de violência como o bullying, que são determinantes no desenvolvimento das relações dentro da escola. O bullying, de acordo com Nesello et all (2014), é a forma de violência tratada com mais frequência nos estudos de associação recentes, realizados com alunos de diversas esferas educacionais, onde ficou demonstrado que os indivíduos do sexo masculino estão constantemente mais associados tanto a condição de autores como de vítimas desse tipo de violência no Brasil, ecoando o machismo presente em nossa cultura. Entretanto, apesar de ser uma situação que abala e desconcerta estudiosos da área da educação, poucas são as propostas efetivas para que este quadro se modifique de fato.

Considerando que, desde a educação infantil, já há registros de comportamentos negativos dos alunos frente aos desafios, e na relação com professores e instituições, cabe à 
ciência da educação encontrar elementos que justifiquem este comportamento agressivo e violento. E propor caminhos para que as relações em ambiente escolar se tornem mais respeitosas e gentis.

Para este estudo consideraremos Educação Infantil a primeira etapa da educação básica, oferecida às crianças entre 0 e 5 anos de idade, que engloba o trabalho das creches e pré-escolas, conforme definição da legislação brasileira na Lei de Diretrizes e Bases 9394/96, artigo 29. A 'criança' a que nos referíamos neste trabalho é o aluno da educação infantil, ser histórico social entre 0 e 5 anos de idade, que, a partir da definição de Kuhlmann e Fernandes (2004) tem sua história marcada pela relação com os adultos, com a cultura e com a sociedade onde vive.

A violência se pauta no desrespeito. Silva (2010) caracteriza a violência dentro da escola como a negação do outro, somada a características que atingem toda a sociedade, como a violação dos direitos humanos, a exclusão, a miséria, o autoritarismo, as desigualdades sociais. Neste sentido, se faz importante compreender como a violência passa a fazer parte da vida das crianças em ambiente educacional, e como uma educação respeitosa e baseada em princípios de amor e compaixão poderia auxiliar o desenvolvimento de personalidades não-violentas nos estudantes.

As crianças não nascem violentas, uma vez que esta é uma característica social e não inata. A violência é uma construção social, um ato de produção de sentido de acordo com Gonçalves (2003). A violência infantil demonstrada nas escolas é aprendida pelas crianças em âmbito familiar ou escolar, com a comunidade que cerca o processo educativo. Adorno (apud AZEVEDO; GUERRA, 2001) caracteriza a violência como uma forma de relação social, inexoravelmente unida aos modelos pelos quais a sociedade produz e reproduz seu modo de existir. A violência é externa às crianças, um comportamento aprendido, que expressa padrões de sociabilidade e modelos de comportamento vigentes no cotidiano de cada criança. Portanto, este comportamento pode não ser aprendido por elas se não forem submetidas a estes padrões, ou se forem constantemente recordadas de que são padrões evitáveis de relacionamento humano rompendo um ciclo vicioso e equivocado, a fim de que não permaneça se repetindo nas relações educacionais destes alunos por toda a sua vida.

A situação atual é desoladora, com a violência presente de forma massiva na educação. Dados de estudos específicos, expostos por Nesello et all (2014), referem ao reconhecimento da violência na escola por $83,4 \%$ dos alunos e $87,3 \%$ dos professores, o preconceito por $76,0 \%$ dos alunos, e 93,3\% dos professores presenciaram situações de discriminação dentro das unidades escolares, tendo a especificidade 'testemunhar bullying' oscilado entre 82,0\% e 83,9\%. Sposito 
(2001) destaca, a partir de estudos também realizados no Brasil, que a violência nas escolas públicas é mais incidente do que nas privadas, considerando os resultados em relação aos contingentes de matrícula nestas redes.

A proposta de mudança das relações interpessoais dentro da escola, iniciando pela educação infantil, traz um horizonte de evolução tanto na diminuição da violência em si como na melhoria das condições de aprendizagem dos alunos, visto que as relações desrespeitosas e violentas dentro das instituições escolares afastam os integrantes da comunidade escolar, dificultando o processo de ensino-aprendizagem. O crescimento do interesse na compreensão da violência no contexto escolar se justifica para além das implicações no processo de integração das crianças ao meio social, "mas pela íntima relação que apresenta com o fracasso de objetivos mais amplos da escola, como educar, ensinar e aprender" (NESELLO at all, 2014, p.18).

O ideal de não-violência remete à filosofia ubuntu, originária da África do Sul. Ramose (1999) esclarece que ubuntu é uma categoria ontológica fundamental do pensamento africano, baseado na luta constante pela harmonia por meio das alianças entre as pessoas. Esta filosofia influencia teóricos em todo o mundo, e se baseia na consciência da relação entre indivíduo e sociedade. Somos seres que se constroem em comunidade, logo todos temos participação em alguma escala no desenvolvimento da personalidade de cada um dos indivíduos. De acordo com Ramose (1999), ubu evoca a ideia de ser, em geral, e a tradução mais próxima para ubuntu, em português, seria 'humanidade para com o outro'.

Se todos somos coparticipantes de todas as ações que acontecem em nosso entorno, se temos responsabilidade sobre nossas ações e somos corresponsáveis pela reação do outro, não há como discutir a violência do aluno sem considerar, profundamente, o papel da comunidade escolar e seus atores na formação deste aluno.

E há de se compreender, ainda, quais as relações entre a violência escolar e a dificuldade de criação de vínculo entre alunos e escolas, de onde emerge a ideia de comunidade escolar hoje bastante enfraquecida em muitas localidades. Charlot (2002) pontua que a violência escolar é uma questão vinculada ao estado da sociedade e às práticas da instituição, mas também está ligada a práticas cotidianas de ensino, que constituem o que chama de coração do reator escolar, questionando os motivos da violência ser mais rara em escolas onde os alunos relatam encontrar sentido e prazer em estudar.

Neste cenário a comunicação não-violenta emerge como uma alternativa para a atual situação, mostrando novos caminhos para as relações em sala de aula, desde as estabelecidas na 
infância. De fato, este estudo debruça-se especialmente sobre as relações estabelecidas durante a infância, uma vez que serão norteadores da relação do aluno com a escola por toda a vida.

\section{O diálogo na escola para crianças}

Falar e ouvir, esta é a base do diálogo, da educação dialógica, e da ausência de violência no processo educativo. Mas não apenas falar e ouvir. $\mathrm{O}$ diálogo exige troca, entre quem fala e quem ouve, entre quem aprende e quem ensina, todos tem algo grandioso a oferecer. Não só falar, como se a verdade fosse propriedade. Muito menos só ouvir, como se não houvesse nada a ser entregue ao outro.

Dialogar é pronunciar nosso mundo. Paulo Freire (2011) associa o diálogo à 'palavra', em referência a ação e reflexão inextricavelmente unidas, interagindo. A palavra, em Freire, é nossa forma de comunicar nosso mundo, e dividi-lo com o outro, ao tempo que o outro faz o mesmo, numa troca contínua. E, é a partir do diálogo que se faz a mudança, porque existir, humanamente, é a capacidade de pronunciar o mundo, e modificá-lo (FREIRE, 2011). O respeito ao outro passa, então, a ter caráter imprescindível para que haja o diálogo, e, sendo a violência a ausência de respeito, ela não pode coexistir em uma relação onde se estabelece diálogo.

A violência tem muitas faces, e as formas físicas de agressão ao corpo são largamente contestadas em nossa sociedade, e legalmente passíveis de condenação em ambiente escolar. A agressão física é objeto de processo criminal, e numa crescente conscientização social este tipo de violência nas escolas tem sido denunciado e cerceado.

Porém, a violência velada, que vem das palavras e atitudes, muitas vezes passa despercebida no contexto em que se insere, o que é ainda mais delicado durante a educação infantil, dada a dificuldade de autodefesa dos alunos pela faixa etária em que se encontram.

A violência tem aumentado nas escolas, segundo Silva (2010), não somente de maneira quantitativa, mas também qualitativa. $\mathrm{O}$ autor atribui esta qualificação da violência pelo aumento de situações de violência velada, sendo ameaças e agressões verbais entre alunos, e entre alunos e professores, os tipos mais recorrentes, e ressalta ainda que "a violência na escola pública está banalizada, provocando inclusive que vários atos deixam até de serem percebidos como violentos" (SILVA, 2010, p.218). Evidentemente este fato não excetua as escolas privadas dos cenários de violência, porém reforça a prevalência na rede pública dos atos violentos que passam despercebidos como tais. 
Muitas situações corroboram para que a violência verbal e psicológica exista e se estabeleça como usual durante a educação escolar de crianças. Um dos fatores é a proximidade entre escola e casa que acontece durante a educação infantil, onde muitas vezes os limites entre o papel dos pais e dos educadores representa uma linha tênue e de fácil - ainda que inadequado transpasse. O conceito maternal da pré-escola, somado a grande quantidade de horas que algumas crianças passam no ambiente escolar e à predominância quase que absoluta de educadores do gênero feminino, constantemente comparadas às mães e tias das crianças em sua conduta profissional, são fatores que dão margem a isto. A escola deve ser o segundo lar, mas não pode ser confundida com o primeiro, com o ambiente familiar.

A princípio, a escola ter papel de casa para as crianças é muito interessante, mas tem uma contrapartida complexa. Se em ambiente escolar se coloca um tipo de educação familiar, os atores da comunidade escolar sentem-se em posição de aplicar aos alunos o mesmo tipo de tratamento que dispensam aos próprios filhos e sobrinhos. Como supracitado, Adorno (apud AZEVEDO; GUERRA, 2001) reconhece a violência como uma reprodução de modos de existir sociais, e, neste caso, os educadores estariam reproduzindo seu fazer diário familiar dentro da escola, numa prática equivocada. Este leque inclui violências físicas, como beliscões e puxões de orelha, até grandes violências simbólicas como impedir a fala, não respeitar as opiniões e solicitações da criança, e o bullying e colocação de apelidos. Ainda que em ambiente familiar estas atitudes sejam reprováveis, elas podem permanecer visto que o cenário doméstico é de responsabilidade familiar, porém são inadmissíveis se realizadas por educadores em ambiente escolar. Estes indivíduos não estão realizando a práxis, e apenas sua inserção lúcida na realidade, em sua situação histórica, pode leva-los à crítica desta situação e ao ímpeto de transformá-la (Freire, 2011, p.75).

Estas formas de violência com a criança ensinam relacionamentos desrespeitosos a estes alunos no ambiente escolar, onde todas as relações devem ser zeladas e pautadas em respeito. Charlot (2002) aponta que a violência que atormenta, que humilha, que tira a fala, é a que tem maiores consequências, especialmente numa instituição escolar da ordem da linguagem e da troca simbólica, onde o uso da força física em especial deve ser rejeitado com veemência.

Os atos violentos que acontecem dentro da escola, sejam de qualquer ordem de violência, sinalizam o que Sposito (2001) caracteriza como dificuldade da unidade escolar na criação de possibilidades para que situações de conflito possam ser resolvidas no âmbito da convivência democrática. E a resolução de conflitos de maneira dialógica e respeitosa é o ponto inicial das relações não-violentas. 
A comunicação não-violenta na escola de educação infantil traz exatamente uma possibilidade de reflexão para educadores, direção e pais de alunos: a violência não sendo uma aceita entre as paredes da escola, seja física ou verbal, em nenhuma relação. Ao tempo que não há nenhum prejuízo para o processo ensino-aprendizagem, por meio do exemplo dialógico as crianças aprendem o valor e a importância das relações respeitosas e recebem a atenção afetiva que a educação infantil demanda, sem a inversão de papéis.

A adoção de formas de comunicação pacífica na educação infantil compreende muito mais do que a atenção ao que dizemos e como dizemos, diz respeito também a como nomeamos os sentimentos das crianças, e como isto pode se mostrar equivocado se as impedimos de sentir, de reconhecer suas necessidades, e de pleitear seu lugar de fala. Ressaltamos aqui novamente a importância do diálogo nas relações educacionais desde a primeira infância, visto que o diálogo é o que permite a pronúncia do mundo, para que se pratique o que Freire (2011) denomina pedagogia humanizadora.

A necessidade imperiosa de que o educador treine a escuta, o ouvir seu aluno em sua realidade e suas necessidades, é um pilar importante para compreendermos o funcionamento da comunicação não-violenta em sala de aula. Não porque o ouvir tenha mais peso do que o falar numa relação dialógica, mas porque é menos trabalhado no processo formativo dos professores. A partir do momento que o educador se coloca no mesmo nível de fala que seu aluno, e o ouve, ele de fato torna possível a troca de experiências, e a integração de todos no ambiente escolar. E este posicionamento é importante para o estabelecimento de relações dialógicas, onde todos os envolvidos no processo de ensino-aprendizagem reconhecem e respeitam a história do outro, não influindo nas questões de autoridade do professor. A violência sempre surge da ausência do respeito, e um lugar onde todos sentem que tem um espaço de fala não abre espaço para ações violentas.

\section{Sobre a comunicação não-violenta}

Comunicação não-violenta é uma teoria bastante discutida nas áreas da comunicação, da educação e da psicologia, visto que sua aplicação interfere diretamente nas relações estabelecidas em todos os âmbitos do convívio humano. A nós, da educação, ela interessa especialmente por tratar da necessidade de afastar todo tipo de violência das estruturas escolares, que são alicerçadas em relacionamentos humanos. 
O propósito da comunicação não-violenta é inspirar a ação compassiva e solidária, e ela é aplicada há cerca de cinquenta anos em todo o mundo, em diversos segmentos sociais. Partindo da premissa de que a violência crescente é reflexo de uma lógica de ação e relação apartada de nossos valores compassivos inatos, a teoria aponta que a forma com que nos comunicamos, não somente com o outro mas também com nós mesmos, nos leva ao choque, ao desrespeito com o diferente, e a emoções dolorosas e/ou destrutivas como raiva, punição, vergonha e culpa. "Ficamos perigosos quando não temos consciência de nossa responsabilidade por nossos comportamentos, pensamentos e sentimentos" (ROSENBERG, 2006, p. 45). No entanto sua aplicação nos processos educativos é recente, em experiências pautadas na inter-relação entre os campos da formação humana.

O trabalho Comunicação Não-Violenta, de Rosenberg (2006), tem em seu título original o subtítulo "uma linguagem para a vida", e é um tratado sobre as relações pautadas em respeito e harmonia entre humanos. Rosenberg (2006) propõe a transposição das questões técnicas da comunicação, e transborda para o afastamento da violência e da agressividade em todos os aspectos do convívio humano, por isso se faz tão pertinente ao campo da educação. O autor se dedica especificamente ao ambiente escolar, tendo obras que coletam apenas estudos sobre a comunicação não-violenta nas escolas.

A educação punitiva, que por meio de castigos ou da retirada de direitos da criança a pune, é entendida na comunicação não-violenta como falha e desnecessária. A punição não ensina nada porque quando "nos submetemos a fazer alguma coisa apenas com o propósito de evitar uma punição, nossa atenção é desviada do valor da própria ação" (ROSENBERG, 2006, p.289). A iminência da possibilidade de ser punida leva a criança a se concentrar nas consequências que podem decorrer da ação, e não na importância das consequências positivas de agir de outra maneira.

A comunicação não-violenta parte da premissa de que todas as situações devem ser negociadas pelas partes. E não desencoraja a disciplina entre as crianças ou no ambiente escolar, mas defende que ela pode ser adquirida com gentileza e de forma consciente e respeitosa. Freire (2011) nos alerta de que autoridade e liberdade caminham juntas, porém devemos negar o autoritarismo que aliena.

Rosenberg (2005) afirma que, para muitas pessoas, parece mais humano utilizar recompensas em detrimento das punições, a fim de educar, mas as duas situações são demonstrações de poder sobre as pessoas, enquanto a comunicação não-violenta é sobre ter poder junto com as pessoas, poder construído a partir de confiança e respeito mútuos. Desta 
forma, não devemos influenciar as crianças a fazer coisas que não querem no ambiente escolar, nem por castigos e nem por prêmios, devemos dialogar para que entendam o propósito das atividades e decidam conscientemente realizá-las. Esta disciplina, estimulada pela vontade de viver de forma compassiva em comunidade, e de proporcionar bem-estar a si e aos outros, encoraja crianças a tornarem-se responsáveis por seus atos, e respeitosos frente ao outro - seja adulto ou outra criança. Além disto trabalha a resiliência para resolver problemas por toda a vida, sem utilizar a violência como ferramenta de força.

A ideia de que haveria uma fórmula mágica para educar a todos não parece muito efetiva, como já se comprovou tantas vezes pela história da educação. Por isso a comunicação nãoviolenta em sala de aula se mostra promissora: por ser caminho, e não equação. $O$ desejo de dignidade, e a compreensão de que o respeito é o valor que torna o diálogo possível, levam os envolvidos na comunidade escolar a se educarem em conjunto.

De uma forma geral, a comunicação não-violenta em sala de aula remete ao desenvolvimento de habilidades sociais por alunos, professores e demais integrantes dos sistemas educacionais, paralelamente às habilidades cognitivas sempre muito pensadas pela escola. É evidente que em alguns momentos em suas vidas, como destaca Rosenberg (2005), as crianças podem se encontrar em situações onde não receberão esta aceitação respeitosa e amorosa, e precisam ser educadas para estas situações também. Eventualmente, em outras situações, eles se encontrem "em escolas onde professores usarão formas de autoridade baseadas em outras filosofias, que acreditem que é necessário batalhar por respeito e amor, ou que se mereça ser punido ou culpado por não se comportar de uma certa maneira” (ROSENBERG, 2005, p.13). O objetivo de trabalhar a comunicação não-violenta com as crianças é que aprendam a permanecer em equilíbrio mesmo em situações adversas, para que consigam encontrar as soluções mais pacíficas possíveis para a resolução de seus problemas, em diversas circunstâncias.

As crianças, desde seu nascimento, estabelecem conexões com os outros e precisam dialogar para entender o mundo. E é daí que surgem os atos violentos, da conexão que não acontece, e do diálogo que não se estabelece. Não há outra forma de diminuir a violência da escola se não levarmos em conta este fato.

A denominação não-violência, utilizada durante todo este trabalho, deriva da teoria filosófica de Mahatma Gandhi que, de acordo com Muller (2007), antes de mais nada, busca exercer a justiça de forma que não entre em contradição com ela. Cecília Meireles, em discurso de homenagem feito no Ministério da Educação em 1948, dedicou a Gandhi a capacidade de ter 
ensinado ao mundo o que é a não-violência, que para ela representava a vitória da reflexão sobre o impulso e da vida sobre a máquina.

O termo 'não-violência' é tradução direta da palavra nonviolence, definida no Dicionário Merriam-Webster como “abstenção da violência enquanto princípio”. Esta nomenclatura nos parece adequada para esta proposta porque a negativa, forte, explicita a urgência de que este tema seja tratado, e de que a violência em todas as formas seja afastada da educação como um todo, sobretudo das crianças.

\section{A comunicação não-violenta e as diversas metodologias de ensino}

Partindo da filosofia da não-violência, que considera as ações violentas retroalimentadas e propõe soluções justas e humanas, a proposta é de que as relações em ambiente escolar sejam mais conscientes e respeitosas. E isto se reflete diretamente no processo de ensino-aprendizagem, independentemente da metodologia de ensino adotada pela instituição escolar, visto que as questões da violência têm interferência direta neste processo. A incorporação dos preceitos da comunicação não-violenta em uma escola não diz respeito diretamente à metodologia adotada, sendo uma proposta de convivência, mas dependendo do nível de rigidez da unidade escolar alguns ajustes serão necessários ao fazer metodológico para permitir os espaços de fala dos alunos.

Em todo o mundo existem iniciativas para uma educação baseada em respeito mútuo, que se inicia numa comunicação pacífica, e grupos para formação de educadores dispostos a exercitar esta filosofia em sala de aula. No Brasil identificamos este movimento em unidades escolares de forma completa em instituições que trabalham com a pedagogia Waldorf e com o método Montessori, mas há também educadores das redes pública e privada que concluem formações e praticam a comunicação não-violenta de forma independente na comunidade escolar, estabelecendo este modelo de diálogo inclusive com os pais dos alunos. De acordo com a ONG Não-Violência nas Escolas, a quantidade de escolas no Brasil autointituladas não-violentas tem aumentado consideravelmente nos últimos anos.

O espaço para novas formas de ensinar é cada dia maior na educação infantil. Considerando que, segundo Khan (2013), cerca de 65\% das crianças que hoje estudam desenvolverão atividades profissionais em empregos que sequer foram inventados, é evidente que a educação precisa se reinventar a todo tempo. "A certeza de mudança, associada com a completa incerteza quanto à natureza precisa dessa mudança, tem implicações profundas e complexas para 
nossa abordagem de educação" (KHAN, 2013, p.182). As metodologias de ensino mais recentes já trazem, em seus grandes eixos, muitas considerações acerca do respeito entre os indivíduos nas relações escolares, e uma preocupação com uma formação inicial para as crianças pautada em harmonia. Entretanto, nenhuma metodologia de ensino, incluindo as mais tradicionais, é impeditivo para que a comunicação não-violenta seja adotada pela comunidade escolar. De forma geral, independente de metodologias, "o mundo mudou [...] fica claro que o foco da nossa educação deve sair do puro aprendizado da matemática, da física e português, para o aprendizado da empatia, das habilidades sociais e do autoconhecimento" (SANTOS, 2019, p.16).

A questão imperativa é: como a escola vê seus alunos? E, mais pontualmente, como cada professor enxerga seu fazer pedagógico, e o quanto se compromete a erradicar a violência das relações encolares. Hart e Hodson questionam: “Quando seus alunos passam pela porta no início do ano letivo, você os vê como seres humanos completos, com seus próprios pensamentos, sentimentos, necessidades, talentos, interesses e dons para compartilhar?” (2004, p. 26). Para as autoras, educadores que percebem seus alunos desta maneira estão aptos a desenvolver uma educação compassiva, baseada na não-violência, e experimentarão sentimentos de admiração e curiosidade durante o ano. Por sua vez, os educadores que já caracterizam os alunos como preguiçosos, perturbadores, bagunceiros, exigentes e/ou rebeldes não estão aptos a desenvolver uma educação compassiva porque partem da premissa de julgamentos moralistas, e possivelmente sentirão ansiedade e medo, que marcarão sua jornada com a turma durante todo o ano. Hart e Hodson (2004) esclarecem que a forma com que os professores 'pensam' seus alunos no início e durante o ano letivo é mais comunicativo a eles do que as palavras que utilizam no cotidiano escolar, e é o que marca suas relações.

A adoção de uma linguagem para a paz, onde a importância das palavras é valorizada para que não se tornem instrumentos de violência, mas onde há também a consideração de que uma relação dialógica tem de ter troca e implica muito mais que falar e ouvir, cabe em qualquer que seja a opção de conteúdo a ser estudado ou formato para o estudo. Por ser uma proposta baseada na satisfação das necessidades próprias e do outro, compassivamente, a aplicabilidade da comunicação não-violenta na escola demanda sobretudo compreender as necessidades dos integrantes da comunidade escolar. De acordo com os estudos de Hart e Hodson (2004), as principais demandas dos alunos são: ser ouvidos, e ser considerados em suas colocações e respeitados em suas ideias. Ao mesmo tempo, estes estudos apontam que educadores gostariam que os estudantes fossem mais responsáveis, engajados e respeitosos. São necessidades que se complementam, mas que precisam ser negociadas para que todos possam ser contemplados. As 
autoras consideram que, a princípio, a adoção da comunicação não-violenta pode parecer mais trabalhosa que a manutenção do fazer pedagógico tradicional, mas que todo o tempo empregado na criação de laços de segurança e confiança, "atendendo às necessidades individuais e aprimorando as habilidades de comunicação, realmente cria o que os educadores mais desejam uma comunidade de aprendizado compassiva em que o aprendizado engajado floresce" (HART e HODSON, 2004, p.15). Evidentemente é necessário que a escola seja um espaço democrático, mas não é imperioso que a metodologia escolhida seja esta ou aquela. A comunicação nãoviolenta é uma filosofia que pode ser aplicada à educação, não um formato metodológico.

A obra freiriana, que dialoga de forma bastante efetiva com as questões da comunicação não-violenta, destaca a necessidade da gentileza para a educação humana. E não tomemos aqui gentileza com um sentido simplista, de boas maneiras: a gentileza freiriana versa sobre a capacidade de ver o mundo com empatia, compreendendo suas dores, e não apenas com simpatia. É ouvir o outro e sentir o que ele nos diz, significar sua fala. No caso da educação infantil, Freire (apud FREIRE; GUIMARÃES, 2003) ressalta a importância de que os educadores dialoguem com as crianças, e, em uma relação de troca, dividam seus mundos. O autor argumenta que é necessário, aos educadores infantis, o uso da imaginação e o respeito pelo mundo dos alunos: "A gente tem medo de deixar a imaginação voar, mas é preciso deixá-la voar! Não voar a ponto de se perder, mas voar, imaginar coisas concretas, coisas possíveis com as crianças" (FREIRE; GUIMARÃES, 2003, p.63). Já a comunicação não-violenta parte da premissa de que "a empatia nos permite perceber nosso mundo de uma maneira nova e ir em frente" (ROSENBERG, 2006, p. 159), considerando ainda que "a empatia está em nossa capacidade de estarmos presentes" (ROSENBERG, 2006, p. 177). Há empatia quando compreendemos que o outro tem papel importante em nossa vida, e nós na dele. Assim sendo, a violência não teria espaço para se desenvolver em um modelo de relações educacionais onde houvesse respeito mútuo, e onde não houvesse a necessidade de sobreposição de poder pela força, para que pudessem surgir bases para relacionamentos não-violentos para a vida.

$\mathrm{Na}$ contramão da utopia e da proposição de conceitos que se chocariam com a realidade da maior parte das escolas, a comunicação não-violenta se mostra uma possibilidade interessante exatamente por não interferir diretamente na rotina escolar. E, ao mesmo tempo, tende a melhorar indiretamente todas as práticas pedagógicas já adotadas pela instituição. Ouvir os sentimentos e necessidades do outro envolve um processo de reflexão longo, notadamente quando o adulto precisa rever seu olhar sobre a criança, e separar este movimento das questões de metodologia facilita o contexto reflexivo. 


\section{A dialogicidade freiriana e a não-violência}

A proposta freiriana de educação é referência quando buscamos resgatar os valores de respeito, amor e humanização na educação, o que a conecta ao conceito de comunicação nãoviolenta na educação. Para Freire (2011), a educação não acontece de A 'para' B, nem de A ‘sobre’ B, e sim de A ‘com' B, mediatizados pelo mundo, e todos precisam ter espaço de fala e de escuta neste processo. A teoria freiriana aponta a emancipação dos sujeitos juntos, assim como Rosenberg (2006) versa sobre a aquisição de poder junto com o outro, e nunca sobre o outro.

Paulo Freire pontua em seus escritos que a violência tem muitas formas de oprimir, que permeiam a sociedade e a escola, e que nem sempre são explícitas. Ele o faz notadamente em Pedagogia do Oprimido (2011) e Pedagogia da Autonomia (2005). A comunicação não-violenta é uma forma de desestruturar a violência que se vê, e também àquela que não se vê, que nos ofende em nossa humanidade. Que tira da criança a sua própria humanidade e rompe sua relação de confiança com a escola.

Dada a necessidade absoluta de dialogicidade para o estabelecimento de relações nãoviolentas, é importante resgatar a perspectiva freiriana de ontologia, considerando que os seres humanos envolvidos na educação, crianças e adultos, estão em constante evolução - e é esta evolução que os faz vivos. Somos, enquanto seres humanos, todos incompletos, inconclusos e inacabados. Desta forma, retomamos o conceito de que não há violência inata e irreversível em algumas crianças, há a violência que foi aprendida por crianças e adultos e que não é permanente, podendo sofrer alterações dependendo das relações estabelecidas com a comunidade.

Em Freire (2014) encontramos a caracterização da violência como desamor, derivada, em larga escala, da falta de capacidade de comunicação entre as pessoas, conceituando a violência como 'antidiálogo'. Logo, uma comunicação não-violenta tem como base o diálogo, sempre. $\mathrm{Na}$ perspectiva freiriana, o diálogo é uma categoria central da construção do conhecimento, e a educação baseada na comunicação não-violenta caminharia para a autonomia.

Ainda que Freire não utilize o termo não-violência para denominar a educação respeitosa e gentil, que considera as necessidades dos alunos de forma integral, podemos encontrar indicativos para ela em muitas de suas obras, em especial em Pedagogia do oprimido (2011), onde ele destaca a necessidade de respeito pelo conhecimento prévio de cada aluno e se debruça sobre a conceituação de diálogo. O autor repudia, ainda, a educação pautada no medo, nos castigos, e nas agressões para manutenção de autoridade, afirmando que não há educação sem amor: “Quem não é capaz de amar seres inacabados não pode educar. Não há educação imposta 
(...) Não há educação do medo" (FREIRE; SHOR, 1986, p. 29). A educação freiriana é compassiva.

A utilização da comunicação não-violenta na educação como um todo se enquadra em três princípios freirianos: o princípio político, pois consideramos educação intervenção na vida coletiva, que deve servir à construção de sociedade livre, justa, humana e democrática, portanto uma educação não-violenta poderia intervir de forma positiva no modelo social vigente; o princípio gnosiológico, porque se a educação se constrói nas relações dialéticas do sujeito com o mundo e com o outro, uma relação menos violenta nas comunidades educacionais interfere na construção do conhecimento pelos alunos; e o princípio axiológico, porque se a educação deve promover a humanização dos sujeitos em contraposição à sua coisificação, ela deve acontecer de forma não-violenta, para que alunos e professores se desenvolvam e se reconheçam em sua humanidade.

\section{Considerações finais: por uma educação dialógica e não-violenta}

O termo educação não-violenta, no Brasil, é utilizado de uma maneira bastante ampla e não diz respeito, unicamente, a utilização de comunicação não-violenta dentro da escola. Esta nomeação, educação não-violenta, é utilizada em nosso país por educadores e também por psicólogos, terapeutas e outros profissionais que não atuam diretamente na educação básica, mas têm por base o trabalho com comunicação não-violenta diretamente relacionado com conceitos disciplinares que preconizam estruturas de ordenamento de ações e ausência de medidas punitivas, sendo estas substituídas por mecanismos de reparação do outro e práticas respeitosas de retratação.

Entretanto, considerando que a comunicação não-violenta é um caminho para a educação para a paz, e que é uma prática que pode ser instituída amplamente apoiada nos pilares freirianos, propomos aqui uma educação infantil dialógica e não-violenta, que considere amorosa e respeitosamente as crianças como indivíduos completos.

A adesão à educação não-violenta em instituições de educação infantil demonstra a possibilidade de novos tipos de relação entre os diversos integrantes da comunidade escolar, atuando de forma consciente num modelo baseado em respeito e gentileza, independente das características tão próprias de cada escola e sua ligação com a comunidade do entorno. Sabemos que modelos escolares não funcionam da mesma forma em todos os lugares, não há como estabelecer um modelo de escola que tenha resultados iguais em todas as comunidades e a 
história da educação nos conta isto repetidamente, mas a proposição de escolas para crianças onde elas sejam integralmente vistas nos parece razoável. Santos (2019) nos recorda que é na infância que aprendemos o olhar que lançamos sobre nós mesmo, e também sobre o mundo. "A maioria de nossas crenças, dos nossos votos e das histórias que contamos a nós mesmos veio da infância. Foi lá que aprendemos a nos relacionar com nós mesmos e com o mundo" (SANTOS, 2019, p.23). E é também na infância que aprendemos a lidar com os conflitos que surgem nas mais diversas relações. Sendo assim, o ambiente escolar da educação infantil, onde as crianças passam parte considerável de sua infância, precisa ser compreendido como um ambiente de formação humana.

O conceito acadêmico para a cultura da educação que considera como um de seus pilares centrais a filosofia da não-violência e do diálogo ainda carece de certa formatação, mas empiricamente a adoção prática de um modelo de comunicação não-violenta em escolas de educação infantil já existe e é notável. Uma coisa é certa: não podemos continuar tratando nossas crianças da mesma forma dentro da escola, sem ouvi-las e desconsiderando seus conhecimentos prévios, seus sentimentos e sua visão de mundo, e esperar resultados diferentes. Se buscamos uma mudança no atual panorama de violência na educação, a mudança deve começar na educação infantil, quando aprendemos o que é escola.

O cenário contemporâneo de violências diversas nos ambientes escolares não é motivador, certamente. Mas a esperança, que é o que nos humaniza a todos, é a grande justificativa para o trabalho de educação compassiva com as crianças. Mesmo sabendo que o caminho para a adoção deste tipo de comportamento é árduo, e que seus resultados levarão algum tempo para serem percebidos na educação como um todo, devemos nos apresentar como atores desta mudança, facilitadores desta conscientização.

Podemos dizer que uma escola onde nenhuma criança teme outra criança ou adulto, onde todos sentem que podem falar e ser ouvidos, e onde todos os envolvidos no processo de ensinoaprendizagem se entendem educadores e aprendizes, é um ambiente onde o diálogo de fato acontece. E uma educação infantil baseada no diálogo e no respeito, que não tem espaço para violência e atitudes punitivas e depreciativas, é um espaço de educação para a humanidade, de educação para a paz.

\section{Referências}

AZEVEDO, M. A.; GUERRA, V. N. A. Mania de bater: a punição corporal doméstica de crianças e adolescentes no Brasil. São Paulo: Iglu, 2001. 
CHARLOT, B. A violência na escola. Revista Sociologias, ano 4, nº, p.432-443. Porto Alegre, 2002.

FREIRE, P. Educaşão como prática da liberdade. São Paulo: Paz e Terra, 2014.

FREIRE, P; SHOR, I. Medo e ousadia: cotidiano do professor. Rio de Janeiro: Paz e Terra, 1986.

FREIRE, P. Pedagogia da autonomia: saberes necessários à prática educativa. São Paulo: Paz e Terra, 2005.

FREIRE, P. Pedagogia do oprimido. São Paulo: Paz e Terra, 2011.

FREIRE, P; GUIMARÃES, S. Sobre educação (Diálogos). São Paulo: Paz e Terra, 2003.

GANDHI, M. K. Autobiografia: minha vida e minhas experiências com a verdade. São Paulo: Palas Athena, 1999.

GONÇALVES, H.S. Infância e violência no Brasil. Rio de Janeiro, Editora FAPERJ, 2003.

HART, S.; HODSON, V.K. The compassive classroom: relationship based teaching and learning. California: Puddledancer Press, 2004.

KHAN, S. Um mundo, uma escola: a educação reinventada. Rio de Janeiro: Intrínseca, 2013.

KUHLMANN JR, M.; FERNANDES, R. Sobre a história da Infância. In: FILHO, L. M. F. (Org.). A infância e sua educação: materiais, práticas e representações. Belo Horizonte: Autêntica, 2004.

MULLER, J. O princípio da não-violência: uma trajetória filosófica. São Paulo: Palas Athena, 2007.

NESELLO F. et all. Características da violência escolar no Brasil: revisão sistemática de estudos quantitativos. Revista Brasileira Saúde Materno Infantil, 14(2), pag.119-136. Recife, 2014.

RAMOSE, Mogobe B. African Philosophy through Ubuntu. Harare: Mond Books, 1999.

ROSENBERG, M. B. Comunicação não-violenta: Técnicas para aprimorar relacionamentos pessoais. São Paulo: Agora, 2006.

ROSENBERG, M. B. Raising children compassionately. California: Puddledancer Press, 2005.

SANTOS, E. Educação não-violenta: como estimular autoestima, autonomia, autodisciplina e resiliência em você e nas crianças. São Paulo: Paz e Terra, 2019.

SILVA, J.M.A.O.; SALLES, L.M.F. A violência na escola: abordagens teóricas e propostas de prevenção. Educar em Revista, nº especial 2, p. 217-232. Curitiba, 2010.

SPOSITO, M.P. Um breve balanço da pesquisa sobre violência escolar no Brasil. Educação e Pesquisa, vol.27, nº1, p. 87-103. São Paulo, 2001. 


\section{Dialogia}

Recebido em: 17 abr. 2019 / Aprovado em: 09 dez. 2019

\section{$\underline{\text { Cite como }}$}

GAIDARGI, Alessandra Maria Martins. Educação infantil dialógica e não violenta.Dialogia, São Paulo, n. 33, p. 246-262, set./dez. 2019. Disponível em:

https://doi.org/10.5585/Dialogia.n33.13602. 